\title{
Results of endoscopic and surgical fistula treatment in oesophagointestinal anastomosis after gastrectomy
}

\author{
Tomasz Miłek ${ }^{1}$, Piotr Ciostek ${ }^{1}$, Robert Petryka ${ }^{2}$, Jakub Słowik ${ }^{2}$, Mirosław Jarosz ${ }^{2}$ \\ ${ }^{1}$ First Chair and Clinic of General, Vascular and Oncological Surgery, Second Faculty of Medicine, Medical University of Warsaw, \\ Warsaw, Poland \\ ${ }^{2}$ Gastrology Department, Food and Nutrition Institute, Warsaw, Poland
}

Videosurgery Miniinv 2015; 10 (4): 515-520

DOI: $10.5114 /$ wiitm.2015.56478

\begin{abstract}
Introduction: Intestinal fistulas occur in 4-8\% of cases of upper gastrointestinal tract surgery. Until now, surgery has been the standard of treating fistulas in oesophagointestinal anastomosis. The use of stents and haemoclips still causes much controversy, but more and more publications present good results with this type of treatment.

Aim: To present results of endoscopic and surgical treatment of fistulas in oesophagointestinal anastomosis after gastrectomy.

Material and methods: A fistula in the oesophagointestinal anastomosis was observed in 23 (4.8\%) patients within an 18-year period. The indications for endoscopic treatment were small fistulas ( $<50 \mathrm{ml} /$ day), and large (>50 $\mathrm{ml}$ day) fistulas in subjects with no symptoms of peritonitis or abscess were treated with implantation a of covered stent. Surgical treatment was performed with a large fistula leading to peritonitis and complicated gangrene of margins and/or the presence of abscess.

Results: Four subjects were treated endoscopically with the use of haemoclips, resulting in 50\% technical and clinical success. We implanted stents in 12 patients. Technical success was achieved in all the patients, yet permanent closure of the fistula was reported for 8 (66\%) subjects. The percentage of patients operated on for fistula was $33 \%$. We recorded 4 deaths in this group.

Conclusions: The use of haemoclips in treatment of small fistulas, and self-expandable, covered stents in treatment of medium and large fistulas, is an effective method that shortens the hospitalisation period and accelerates introduction of oral nutrition while reducing the number of fatal complications.
\end{abstract}

Key words: oesophagointestinal anastomosis, intestinal fistula.

\section{Introduction}

Healing complications of oesophagointestinal anastomosis after total gastrectomy are associated with remarkable mortality reaching $70 \%$ in older reports and $35 \%$ and more in reports from the last few years [1-5]. Intestinal fistulas occur in $4-8 \%$ of cases of upper gastrointestinal tract surgery [6-8]. Despite the appearance of new surgical techniques, the number of fistula healing complications remains constant, which means prolonged hospitalisation and increased cost of treatment [7, 8]. Until now, the gold standard of treating fistulas in oesophagointestinal anastomosis has been surgery or drainage of the anastomotic area. This is currently not recommended as a routine procedure. Reoperation is difficult to perform on an infected operating field and carries a risk of further complications. On the other

\section{Address for correspondence}

Tomasz Miłek MD, First Chair and Clinic of General, Vascular and Oncological Surgery, Second Faculty of Medicine, Medical University

of Warsaw, 8 Kondratowicza St, 03-242 Warsaw, Poland, phone: +48 604422 345, e-mail: tomasz_milek@wp.pl 
hand, conservative external drainage of the fistula is a long-term procedure and requires several weeks' treatment with parenteral nutrition. In the last few years, new methods have been presented, in the form of case reports and studies on small groups of patients, which are based on a minimally invasive endoscopic technique. This involves implantation of self-expandable, covered stents in the area of the fistula and in the case of small fistulas with a slight insufficiency of anastomosis, connecting intestinal walls using haemoclips. The procedure is accompanied by drainage of the anastomosis area. The use of stents and haemoclips still causes much controversy, but more and more publications present good results of this type of treatment.

\section{Aim}

The study objective is to present the results of endoscopic and surgical treatment of fistulas in oesophagointestinal anastomosis after gastrectomy and to recreate the continuity of the gastrointestinal tract by the Roux-Y method.

\section{Material and methods}

Six hundred and thirty patients were treated for gastric cancer in the years 1996-2014. Four hundred and eighty-seven patients had Roux-Y oesophagointestinal anastomosis with the use of staplers.

One hundred and forty-three subjects underwent partial gastric removal and reconstruction of the gastrointestinal tract continuity by means of a different method, so they were not included in the study. The operation technique was based on anastomosis of the oesophageal stump with the side of the first loop of the small intestine by means of a circular stapler. Eighty-nine anastomotic connections were performed after left-sided thoracotomy with the oesophageal stump in the posterior mediastinum, and 398 connections of the small intestine with the abdominal section of the oesophagus were performed. A fistula in the oesophagointestinal anastomosis was observed in 23 (4.8\%) patients. They included 17 men and 6 women aged 59-67 years (mean: 64 years). Four leaks occurred in the left pleural cavity and 19 within the peritoneal cavity. The first sign of leakage was increased temperature, stomach ache with no overt peritoneal symptoms, as well as dyspnoea if the connection was performed within the thorax. Additional tests revealed increased leukocy- tosis, C-reactive protein (CRP) and a reduced albumin level. There was no early confirmation of a fistula, i.e. when clinical symptoms were concomitant with the occurrence of intestinal content in the drain placed in the areas of anastomosis. The contents of the gastrointestinal tract usually appeared 12-24 h after clinical symptoms. The next stage was to perform fluoroscopy with water contrast in order to confirm the presence and location of the fistula, as well as computed topography in order to assess the opening in the connection and the location of fluid prior to drainage. Closure of fistulas was performed by means of endoscopy and surgical treatment. The result of treatment was assessed with regard to a technical success and clinical success. Technical success was defined as closure of the fistula following endoscopic or surgical treatment. Clinical success was defined as significant reduction of the fistula and remission of systemic infection symptoms. In these subjects the fistula was closed after conservative treatment.

The indications for endoscopic treatment were small fistulas ( $<50 \mathrm{ml} /$ day) and the fact that patients treated with surgery more often had significant respiratory and cardiological complications.

Endoscopic closure of fistulas was performed under intravenous anaesthesia (sedation) following midazolam administration $(0.05 \mathrm{mg} / \mathrm{kg})$. When the fistula was made visible, haemoclips were applied to its borders to close the fistula opening. Then, water contrast was applied by means of endoscopy to confirm that the connection was tight. Parenteral nutrition was introduced after the procedure. On day 6 , a leak test was performed with water contrast, followed by introduction of oral nutrition. Large fistulas (> $50 \mathrm{ml} /$ day) in subjects with no symptoms of peritonitis or abscesses were treated with implantation of covered stents (Photos 1 and 2). Also in this case subjects were treated with parenteral nutrition. The location of the stent was checked 2 days after implantation with an X-ray. Oral nutrition was introduced on day 2 if no clinical features of fistula were present. The final decision on endoscopic closure of the fistula was made during the procedure.

Surgical treatment was performed under general anaesthesia on subjects with a large fistula leading to peritonitis and complicated gangrene of margins and/or the presence of abscess. Surgical treatment involved complete reconstruction of the connection and application of nutritive microjejunostomy. A tightness test was also performed on day 6 . If 


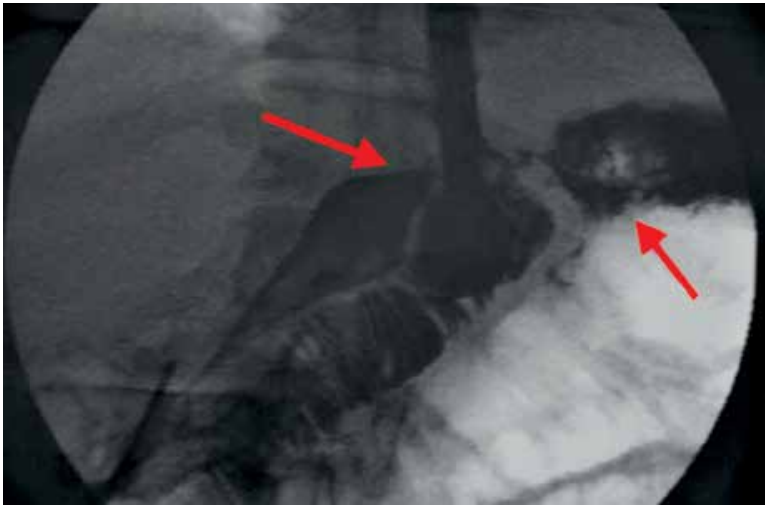

Photo 1. Fistula in anastomosis

there were no symptoms of fistula, oral nutrition was initiated.

The procedures were supplemented with drainage of the fistula area and targeted antibiotic therapy.

Average time between the operation and the appearance of the fistula was 7 days (6-13). Post-treatment follow-up was performed every 3 months in ambulatory conditions.

\section{Results}

In the period 1996-2014, 487 procedures of gastric removal were performed with reconstruction of

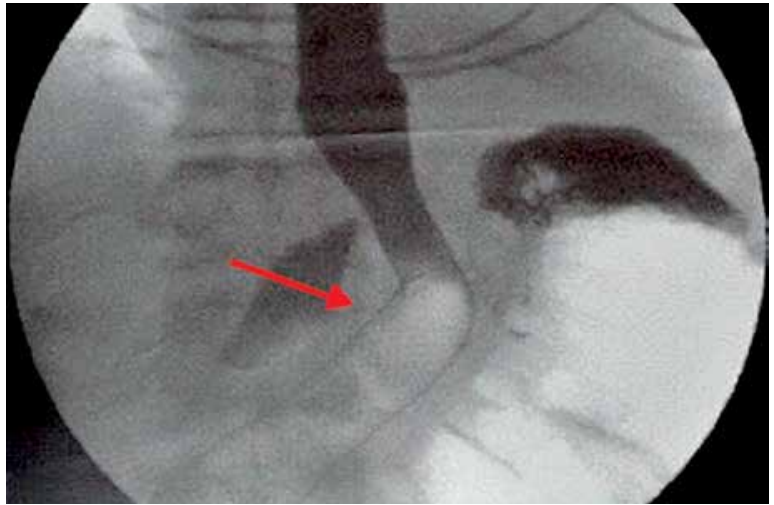

Photo 2. Stent after implantation

the gastrointestinal tract continuity by the Roux- $Y$ method. A fistula in the oesophagointestinal anastomosis was observed in 23 subjects. The average age of the patients was 64. All the patients had significant comorbidities and post-operative complications related both to a complex operation and the occurrence of fistula (Table I). Advanced stage of the cancer and weight loss exceeding $10 \%$ often required introduction of parenteral nutrition and blood transfusion prior to the operation. The operation was longer in those subjects and often required removal of other lesions in organs of the abdominal

Table I. Comorbidities

\begin{tabular}{|c|c|c|c|}
\hline \multirow[t]{2}{*}{ Parameter } & \multicolumn{3}{|c|}{ Fistula treatment -23 subjects } \\
\hline & Haemoclip - 4 & Stent -12 & Surgery -7 \\
\hline Comorbidities: & & & 1 \\
\hline Post-myocardial infarction status & 1 & 1 & \\
\hline COPD & 2 & 4 & \\
\hline \multicolumn{4}{|l|}{ Diabetes } \\
\hline \multicolumn{4}{|l|}{ Major post-operative complications: } \\
\hline Cardiovascular & 2 & 2 & 1 \\
\hline Respiratory & 2 & 6 & 4 \\
\hline Renal impairment & & 1 & 1 \\
\hline \multicolumn{4}{|l|}{ Hepatic impedimenta } \\
\hline \multicolumn{4}{|l|}{ Surgical complications (excluding fistula): } \\
\hline Pancreatic fistula & - & 2 & 1 \\
\hline Bleeding in the gastrointestinal tract & 1 & 1 & 3 \\
\hline Peritoneal or pleural abscess & - & - & 7 \\
\hline Wound festering & 2 & 3 & 7 \\
\hline
\end{tabular}


cavity. Table II shows the stage of cancer and the operation type. The observation period was 12 months - Table III. The patients arrived for follow-up every
3 months. All the patients with implanted stents reported pain located in the thoracic region during the follow-up visits. Further hospital follow-up was not

Table II. Stage and TNM scale

\begin{tabular}{|c|c|c|c|c|}
\hline Parameter & $\begin{array}{c}\text { Total } \\
(n=23)\end{array}$ & $\begin{array}{l}\text { Haemoclips } \\
\quad(n=4)\end{array}$ & $\begin{array}{l}\text { Stents } \\
(n=12)\end{array}$ & $\begin{array}{l}\text { Surgical } \\
\text { treatment } \\
\quad(n=7)\end{array}$ \\
\hline Gender (M/F) & $17 / 6$ & $3 / 1$ & $8 / 4$ & $6 / 1$ \\
\hline Mean age & $59-67 / 64$ & & & \\
\hline Tumour - pyloric region & & 0 & 0 & 0 \\
\hline Tumour - body & & 3 & 4 & 2 \\
\hline Tumour - cardia & & 1 & 3 & 3 \\
\hline Tumour - whole stomach & & 0 & 5 & 2 \\
\hline Gastrectomy + D1 lymphadenectomy & $4-17 \%$ & 1 & 2 & 1 \\
\hline Gastrectomy + D2 lymphadenectomy & $13-57 \%$ & 3 & 6 & 4 \\
\hline Gastrectomy + D3 lymphadenectomy & $6-26 \%$ & 0 & 4 & 2 \\
\hline Operation time, mean (range) [min] & $150(115-195)$ & $180(170-210)$ & $175(140-240)$ & $160(140-250)$ \\
\hline Mean hospitalisation period & & $17-25 / 19$ & $15-23 / 17$ & $26-34 / 29$ \\
\hline Deaths & & 0 & $3-25 \%$ & $4-57 \%$ \\
\hline Blood transfusion prior to operation & & 0 & $2-17 \%$ & $2-29 \%$ \\
\hline Blood transfusion following operation & & $4-100 \%$ & $12-100 \%$ & $7-100 \%$ \\
\hline Weight loss prior to operation exceeding $10 \%$ & & $4-100 \%$ & $12-100 \%$ & $7-100 \%$ \\
\hline Multi-organ removal - M parameter & $\begin{array}{l}\text { MO } \\
\text { M } 1\end{array}$ & $\begin{array}{l}4 \\
0\end{array}$ & $\begin{array}{l}9 \\
3\end{array}$ & $\begin{array}{l}5 \\
2\end{array}$ \\
\hline T parameter & $\begin{array}{l}\mathrm{T} 2 \\
\mathrm{~T} 3 \\
\mathrm{~T} 4\end{array}$ & $\begin{array}{l}1 \\
3 \\
0\end{array}$ & $\begin{array}{l}0 \\
9 \\
3\end{array}$ & $\begin{array}{l}1 \\
4 \\
2\end{array}$ \\
\hline N parameter & $\begin{array}{l}\text { N1 } \\
\text { N2 } \\
\text { N3 }\end{array}$ & $\begin{array}{l}1 \\
2 \\
1\end{array}$ & $\begin{array}{c}0 \\
12 \\
0\end{array}$ & $\begin{array}{l}2 \\
5 \\
0\end{array}$ \\
\hline Technical success of fistula closure & & $2(50 \%)$ & $12(100 \%)$ & $7(100 \%)$ \\
\hline Clinical success of fistula closure & & $2(50 \%)$ & $8(66 \%)$ & $7(100 \%)$ \\
\hline Reoperation & & $\begin{array}{l}2(50 \%)-\text { stent } \\
\text { implantation }\end{array}$ & $4(34 \%)$ & 0 \\
\hline
\end{tabular}

Table III. Follow-up

\begin{tabular}{|lccc|}
\hline Observation period [months] & Haemoclips/stent & Stent & Operation \\
\hline 3 & $4-100 \%$ & $7-58 \%$ & $3-100 \%$ \\
\hline 6 & $4-100 \%$ & $7-58 \%$ & $3-100 \%$ \\
\hline 9 & $2-50 \%$ & $5-42 \%$ & 0 \\
\hline 12 & $2-50 \%$ & $4-33 \%$ & 0 \\
\hline
\end{tabular}


possible due to cancer cachexia and the poor general health condition of the patients.

\section{Discussion}

Intestinal fistulas occur in 4-8\% of cases of upper gastrointestinal tract surgery [6-8]. They significantly increase mortality and decrease long-term survival [1-5]. Despite the appearance of new surgical techniques, the number of fistula healing complications remains constant, which results in prolonged hospitalisation and increased cost of treatment [7, 8]. Until now, the gold standard of treating fistulas in oesophagointestinal anastomosis has been surgery or drainage of the anastomotic area. This is currently not recommended as a routine procedure. Reoperation is difficult to perform on an infected operating field and carries a risk of further complications. On the other hand, conservative external drainage of the fistula is a long-term procedure and requires several weeks' treatment with parenteral nutrition. One of the first to describe an endoscopic method of fistula closure was Pross [9-22]. He used a vicryl net with fibrin to close the fistula. In the last few years, new methods have been presented, in the form of case reports and studies on small groups of patients, which are based on a minimally invasive endoscopic technique. The procedure involves implantation of self-expandable stents in the area of the fistula and, in the case of small fistulas with a slight insufficiency of anastomosis, connecting intestinal walls using haemoclips. The procedure was supplemented with drainage of the anastomosis area, and usually was ultrasound-guided. Bege et al. [23] reported $100 \%$ technical success of oesophagointestinal fistula closure using clips and tissue glue. In our study, intestinal fistula occurred in $4.8 \%$ of patients undergoing an operation due to advanced gastric cancer with reconstruction of the gastrointestinal tract continuity by the Roux-Y method. Four subjects were treated endoscopically using haemoclips, resulting in 50\% technical and clinical success. All the procedures were performed by experienced specialists in endoscopic treatment. Such a low success rate can be explained by the fact that the procedure is very difficult and involves implantation of clips approaching the anastomosis margins and careful manipulation of the apparatus to avoid enlargement of the fistula. At the same time, the remaining subjects underwent implantation of a self-expandable stent with a good technical and clinical effect. We did not record deaths in this group of patients. Another technique that we used for treating fistulas in oesophagointestinal anastomosis was implantation of a self-expandable covered stent in the area of the fistula. An indication for this procedure was the presence of a fistula exceeding $50 \mathrm{ml}$ of daily secretion, which suggested a significant insufficiency of anastomosis and was confirmed by tomography. The beginnings of stent usage in upper gastrointestinal tract disease involved stent implantation in the place of unresectable oesophageal cancer, which caused obstruction and no possibility of oral nutrition. The use of stents to close an oesophagointestinal fistula goes not so far back in the past $[9,10,20]$. The advantages of this method include the short time of the procedure and the possibility of oral nutrition on the next day, thus limiting expensive parenteral nutrition [11-13]. Technical success was reported in the literature to reach $95-100 \%$. Clinical success, on the other hand, that is fistula closure, was achieved in $78-89 \%$ of subjects [14-17]. A major complication of the procedure, decreasing its efficacy, was stent migration $[18,19]$. In our study, we implanted stents in 12 patients. We achieved technical success in all the patients, yet permanent closure of the fistula was reported for 8 (66\%) subjects. Complete stent migration was observed in 3 patients. In 1 case, the fistula was reduced and conservative treatment was continued, which resulted in fistula closure. Three patients underwent an operation in which the fistula was closed with a single surgical stitch following stent removal. The operations were supplemented with drainage of the anastomosis area. We recorded 3 deaths in this group of patients. They resulted from fistula recurrence in subjects operated on and respiratory and multi-organ complications. Surgical treatment of fistulas with drainage of the fistula area is the most common. In a multi-centre study including 3018 subjects, fistula in the anastomosis was observed in $2.1 \%$ [2]. Forty percent of subjects were treated with surgery. The other patients were subject to conservative treatment with the use of parenteral nutrition, antibiotics and closed fistula drainage. As many as $59 \%$ of operated subjects experienced complications in the form of recurrent fistulas (13\%), small bowel obstruction (8\%), wound infection (19\%), respiratory failure $(10 \%)$ and multiple organ failure (16\%). Ten percent of the subjects operated on died. 
The duration of the operation depended on the general condition of the patient. Nevertheless, an early operation gave more chances for anastomosis healing. This behaviour was explained by the lack of local tissue infection and increased technical difficulty of the operation resulting from tissue fragility following operation postponement. In our study, the percentage of patients operated for fistula was $33 \%$. We recorded 4 deaths in this group, i.e. $57 \%$ of the subjects operated on. The main causes of death were respiratory complications leading to prolonged respiratory therapy and symptoms of increasing multiple organ failure.

\section{Conclusions}

The use of endoscopic techniques in treatment of oesophagointestinal fistulas after gastrectomy caused by cancer is an alternative to traditional surgical treatment. The use of haemoclips in treatment of small fistulas, and self-expandable, covered stents in treatment of medium and large fistulas, is an effective method that shortens the hospitalisation period and accelerates introduction of oral nutrition while reducing the number of fatal complications.

\section{Conflict of interest}

The authors declare no conflict of interest.

\section{References}

1. Kauer WK, Stein HJ, Dittler HJ, Siewert JR. Stent implantation as a treatment option in patients with thoracic anastomotic leaks after esophagectomy. Surg Endosc 2008; 22: 50-3.

2. Alanezi K, Urschel JD. Mortality secondary to esophageal anastomotic leak. Ann Thorac Cardiovasc Surg 2004; 10: 71-5.

3. Lerut T, Coosemans W, Decker G, et al. Anastomotic complications after esophagectomy. Dig Surg 2002; 19: 92-8.

4. Whooley BP, Law S, Alexandrou A, et al. Critical appraisal of the significance of intrathoracic anastomotic leakage after esophagectomy for cancer. Am J Surg 2001; 181: 198-203.

5. Griffin SM, Lamb PJ, Dresner SM, et al. Diagnosis and management of a mediastinal leak following radical oesophagectomy. Br J Surg 2001; 88: 1346-51.

6. Meyer L, Meyer F, Dralle H, et al; East German Study Group for Quality Control in Operative Medicine and Regional Development in Surgery. Insufficiency risk of esophagojejunal anastomosis after total abdominal gastrectomy for gastric carcinoma. Langenbecks Arch Surg 2005; 390: 510-6.

7. Sauvanet A, Mariette C, Thomas P, et al. Mortality and morbidity after resection for adenocarcinoma of the gastroesophageal junction: predictive factors. J Am Coll Surg 2005; 201: 253-62.
8. Lang H, Piso P, Stukenborg C, et al. Management and results of proximal anastomotic leaks in a series of 1114 total gastrectomies for gastric carcinoma. Eur J Surg Oncol 2000; 26: 168-71.

9. Schmidt H, Managold BC, Struker D, Grund KE. Anastomotic insuffiences of the esophagus early surgical endoscopy and endoscopic therapy. Kongress Dtsch Ges Chir Kongr 2001; 118: 278-81.

10. Sarper A, Oz N, Cihangir C, et al. The efficacy of self expanding metal stents for palliation of malignant esophageal strictures and fistulas. Eur J Cardiothorac Surg 2003; 23: 794-8.

11. Portanova M. Successful enteral nutrition in the treatment of esophagojejunal fistula after total gastrectomy in gastric cancer patients. World J Surg Oncol 2010; 8: 71.

12. Akashi Y, Hiki N, Nunobe S, et al. Safe management of anastomotic leakage after gastric cancer surgery with enteral nutrition via a nasointestinal tube. Arch Surg 2012; 397: 737-44.

13. Soeters PB, Ebeid AM, Fischer JE. Review of 404 patients with gastrointestinal fistulas. Impact of parenteral nutrition. Ann Surg 1979; 190: 189-202.

14. Annapillai A, Ramachandran B, Ponniah S, et al. Esophagojejunal anastomotic leak managed with self expandable metallic stent. Dig Endosc 2013; 4: 13-5.

15. Facy O, Goergen M, Poulain V, et al. Minimally invasive management of postoperative esophagojejunal anastomotic leak. Surg Laparosc Endosc Percutan Tech 2014; 24: 183-6.

16. Fernandez A, Vila J, Vazquez S, et al. Self-expanding plastic stents for the treatment of post-operative esophago-jejuno anastomosis leak. A case series study. Rev Esp Enferm Dig 2010; 102: 704-10.

17. Kim Y, Shin S, Lee H, et al. Endoscopic management of anastomotic leakage after gastrectomy for gastric cancer: how efficacious is it? Scand J Gastroenterol 2013; 48: 111-8.

18. Lee S, Ahn J, Jung $\mathrm{H}$, et al. Clinical outcomes of endoscopic and surgical management for postoperative upper gastrointestinal leakage. Surg Endosc 2013; 27: 4232-40.

19. Martin R, Duvall R, Ellis S, Scoggins C. The use of self-expanding silicone stents in esophageal cancer care: optimal pre-, peri-, and postoperative care. Surg Endosc 2009; 23: 615-21.

20. Safranek J, Geiger J, Vesely V, et al. Esophageal stents for less invasive treatment of mediastinitis. Videosurgery Miniinv 2014; 9: $1-5$.

21. Wang Q, Liu ZS, Qian Q, et al. Treatment of upper gastrointestinal fistula and leakage with personal stage nutrition support. World J Gastroenterol 2008; 14: 5073-7.

22. Oh SJ, Choi WB, Song J, et al. Complications requiring reoperation after gastrectomy for gastric cancer: 17 years experience in a single institute. J Gastrointest Surg 2009; 13: 239-45.

23. Bege T, Emungania O, Vitton $\mathrm{V}$, et al. An endoscopic strategy for management of anastomotic complications from bariatric surgery: a prospective study. Gastrointest Endosc 2011; 73: 238-44.

Received: 25.05.2015, accepted: 21.11.2015. 